УДК 378.1 + 658.2

Вавдіюк Н.С., д.е.н., професор

Завідувач кафедри менеджменту

Vavdiiuk N., Doctor of Economics Science, Professor

Head of Management Department

https://orcid.org/0000-0001-9100-3722

Подолян Д.В., аспірант кафедри підприємництво,

торгівля та біржова діяльність

Podolian D., Postgraduate student of the Department of

Entrepreneurship, Trade and Exchange Activities

https://orcid.org/0000-0001-7335-3964

\title{
МЕТОДИЧНИЙ ПІДХІД ДО АНАЛІЗУ СТВОРЕННЯ СТАРТАПІВ СТУДЕНТАМИ
}

\author{
Луцьький національний технічний університет
}

\begin{abstract}
У статті розглянуто методичні підходи до аналізу стартапів, створених студентами: UBI Global World Rankings of Business Incubators \& Accelerators (Швеція), методичний підхід сформований на основі моделі «потрійної спіралі» Г. Іцковіца і Л. Лейдесдорффа (Росія), The Female Founders Monitor (FFM) (Німеччина), European University Association EUA Study (Бельгія), The State of European Tech (Великобританія), Startup Ranking (Перу), European Startup Monitor (Німеччина), QS World University Rankings (Великобританія), German Startup Monitor (Німеччина), Global Innovation Index (Швейцарія), Startup Friendliness Index (США). Описано переваги та недоліки використання кожного підходу. У розрізі вищеописаних методичних підходів виокремлено показники, що досліджують стартапи, створені студентами. Здійснено їхній розподіл відповідно до життєвого циклу стартапу та підходів до управління. Їхнє дослідження дозволило сформувати авторський методичний підхід до аналізу створення стартапів студентами. Вона охоплює напрями, вибір яких спирається на наступні визначальні ознаки: аналіз розвитку підприємницьких університетів; аналіз практики розвитку бізнес-інкубаторів при університетах зарубіжних країн; аналіз сфери реалізації та способів фінансування стартапів, створених студентами; аналіз засновників стартапів. Відповідно до 4-х визначальних ознак, здійснено вибір показників для проведення аналізу створення стартапів студентами.
\end{abstract}

Ключові слова: cтартап, аналіз, студенти, управління, методичний підхід, рейтинг, бізнесінкубатор.

\section{METHODOLOGICAL APPROACH TO ANALYSIS CREATING STARTUPS BY STUDENTS}

\author{
Lutsk National Technical University
}

The article considers methodical approaches to the analysis of startups created by students: UBI Global World Rankings of Business Incubators \& Accelerators (Sweden), methodical approach formed on the basis of the "triple spiral" model by G. Itzkovitz and L. Leidesdorf (Russia), The Female Founders Monitor (FFM) (Germany), European University Association EUA Study (Belgium), The State of European Tech (UK), Startup Ranking (Peru), European Startup Monitor (Germany), QS World University Rankings (UK), German Startup Monitor (Germany), Global Innovation Index (Switzerland), Startup Friendliness Index (USA). The present study analyzes advantages and disadvantages of using each approach. In this article selected indicators, exploring startups created by students. The author has mapped the way in which these indicators are divided according to the startup life cycle and management approaches. The author has mapped the way in which methodical approach to the analysis of creation of startups by students. The emphasis has been placed on directions, the choice of which is based on the following defining features: analysis of the development of business universities; analysis of the practice of business incubators development at universities of foreign countries; analysis of the scope of implementation and methods of financing startups created by students; analysis of startup founders. In accordance with the 4 defining features, the choice of indicators for the analysis of the creation of startups by students.

Key words: startup, analysis, students, management, methodical approach, rating, business incubator. 
Постановка проблеми у загальному вигляді та їі зв'язок 3 важливими науковими та практичними завданнями. Щороку збільшується кількість створених та реалізованих стартапів. 3 огляду на набуття популярності стартапів та зростання їх ролі у розбудові нових ринкових ніш, пріоритетним є формування методичного підходу до аналізу створення стартапів студентами.

Аналіз останніх досліджень і публікацій, в яких започатковано вирішення проблеми. Дослідженням створення стартапів присвячено праці таких вітчизняних учених, як Артемова В.І., Малова А.С., Мухачева А.В. [1] та ін. Аналіз реалізації стартапів розглядається у наступних міжнародних методиках: UBI Global World Rankings of Business Incubators \& Accelerators [11], методичний підхід сформований на основі моделі «потрійної спіралі» Г. Іцковіца і Л. Лейдесдорффа [1], The Female Founders Monitor (FFM) [9], European University Association EUA Study [3], The State of European Tech [10], Startup Ranking [8], European Startup Monitor [2], QS World University Rankings [6], German Startup Monitor [4], Global Innovation Index [5], Startup Friendliness Index [7]. Віддаючи належне високому рівню наукових напрацювань, слід зазначити, що недостатньо уваги все ж приділяється розробці методичного підходу до аналізу створення стартапів студентами.

Мета статті полягає у формуванні методичного підходу до аналізу стартапів, створених студентами.

Виклад основного матеріалу дослідження 3 повним обгрунтуванням отриманих наукових результатів. Міжнародні рейтинги, методичні підходи та індекси допомагають виявити тенденцію розповсюдження стартап-руху у світі, виявити характеристики, що допомагають створювати проекти.

Отже, розглянемо методичні підходи до аналізу стартапів, створених студентами.

UBI Global World Rankings of Business Incubators \& Accelerators (Швеція) [11]. UBI Global міжнародна дослідницька організація, основна мета якої - оцінка та аналіз ефективності бізнес-інкубаторів та акселераторів по цілому світі. Мережа UBI Global щороку проводить дослідження стартапів, що були створені за підтримки університетів. Так, UBI Global World Rankings of Business Incubators \& Accelerators охоплює більше 90 країн світу та понад 1200 інкубаційних програм, які пов'язані з університетами.

Показники UBI Global World Rankings of Business Incubators \& Accelerators, що досліджують стартапи, створені студентами [11]:

- рейтингування світових бізнес-інкубаторів, що створенні поза межами університетів, але співпрацюють 3 ними;

- рейтингування світових бізнес-інкубаторів, що створенні в університетах;

- перелік університетських програм бізнес-інкубації та акселерації.

Показники UBI Global, які не досліджують стартапи, створені студентами:

- рейтингування світових бізнес-акселераторів (не включає інформацію про досліджувані стартапи);

- рейтингування приватних акселераторів, які не надають підтримки студентським проектам.

Методичний процес UBI Global World Rankings of Business Incubators \& Accelerators складається 3 таких етапів:

1) збір даних;

2) обробка даних;

3) оцінка даних;

4) рейтингування.

Аналітичні дані, які включає UBI Global World Rankings of Business Incubators \& Accelerators дозволяють оцінити ефективність розвитку університетських інкубаторів та виявити найбільш успішні. 
Перевагами UBI Global World Rankings of Business Incubators \& Accelerators є те, що у дослідження включено достатня кількість даних по університетських інкубаторах різних країн світу; результати подані у вигляді рейтингів; є можливість порівняти дані поточного періоду з минулим.

Недоліком рейтингу, що пропонує UBI Global World Rankings of Business Incubators \& Accelerators $€$ те, що він $є$ вузькоспеціалізованим - базується на дослідженні інкубаторів та акселераторів. Це робить неможливим проведення аналізу інших визначальних факторів, що стосуються стартапів, створених студентами.

Методичний підхід до оцінки функціонування бізнес-інкубаторів при університетах запропонований Д. І. Артемовою та А. С. Маловою (Росія) [1, с. 81]. Даний методичний підхід сформований на основі моделі «потрійної спіралі» Г. Іцковіца і Л. Лейдесдорффа. Опираючись на модель «потрійної спіралі», науковці розглядали інноваційність студентів, як союз між владою, бізнесом і університетом.

Методичний підхід охоплює наступні показники:

- характеризує стартапи, створені студентами: інкубаторів;

1) дослідження цілей створення i функціонування університетських бізнес-

2) аналіз типів вишів, при яких створюються бізнес-інкубатори;

3) визначення особливостей відбору проектів для підтримки;

4) оцінка ініціаторів створення і джерел фінансування;

- не характеризує стартапи, створені студентами:

5) участь бізнес-інкубаторів у розвитку інноваційних систем за принципами моделі «потрійний спіралі».

Перевагою даного методичного підходу є те, що він дає можливість визначення особливостей університетських бізнес-інкубаторів та їх вкладу в розвиток інноваційних систем. Основним недоліком - відсутність емпіричних даних, які потрібні для проведення аналізу.

The Female Founders Monitor (FFM) (Німеччина) [9]. Моніторинг жінокзасновниць стартапів (в т.ч. при університетах окремих країн світу). У FFM включено наступні показники для аналізу стартапів, створених студентами [9]:

1) розподіл проектів за статтю;

2) структурування команди та кількість працівників;

3) аналізування груп споживачів (стратегічна орієнтація);

4) оцінка фінансування;

5) партнерські відносини.

Показники FFM, які не використовуються для аналізу стартапів, створених студентами:

1) оцінка співпраці серед компаній (показник, містить дані про фірми, що співпрацюють між собою);

2) пріоритетні корпоративні стратегії (інформація, узагальнена у даному анкетуванні стосується лише жіночих стартапів, а отже, є неповною та суб'єктивною).

Основним недоліком The Female Founders Monitor $\epsilon$ те, що його дослідження спрямоване лише на засновників жіночої статті. Це, у свою чергу, не дає можливості оцінити усіх студентів-стартаперів.

European University Association EUA Study (Бельгія) [3]. Асоціація університетів Європи проводить дослідження (раз у 3 роки) - The Role of Universities in Regional Innovation Ecosystems, в якому знаходять своє відображення такі оціночні групи:

1) оцінка регіонів щодо активності стартапів, створених студентами;

2) анкетування респондентів щодо можливості співпраці та взаємодії бізнесу та університету; 
3) аналіз способів обміну та передачі знань від ЗВО до студента.

Показники EUA Study, що не досліджують стартапи, створені студентами:

1) динаміка фінансування університетів;

2) оцінка підвищення якості діяльності 3ВО;

3) аналіз співпраці між ЗВО країн Свропи;

Для EUA Study характерним є використання методу якісного аналізу створення стартапів при ЗВО. Зважаючи на це, ключовим недоліком можна вважати суб'єктивність отриманих даних та їх нечіткі результати.

Startup Ranking (Перу) [8]. Всесвітній рейтинг включає оцінку наймасштабніших стартапівських екосистем. Методологія Startup Ranking заснована на кількісному алгоритмі. Рейтинг ооплює понад 100 тисяч бізнес-проектів, в тому числі, 60 тисяч стартапів. Недоліком Startup Ranking $є$ те, що він не розмежовує стартапи, що були створені з / без участі ЗВО.

The State of European Tech - щорічне аналітичне дослідження, яке складає венчурна компанія Atomico (Великобританія) [10]. Моніторинг базується на наступних групах показників:

1) аналіз стану європейських технологій, створених стартап-компаніями;

2) оцінка інвестиції вкладених у стартапи;

3) аналіз інвесторів;

4) аналіз стартаперів за статевим розподілом;

5) призначення проектів та локалізація їх реалізації.

Показники The State of European Tech, які не використовуються для аналізу стартапів, створених студентами:

1) частка респондентів-засновників, які залучили зовнішнє фінансування у розрізі етнічної приналежності (не $\epsilon$ доцільним проведення аналізу стартапів, створених студентами відповідно до даного критерію);

2) анкетування засновників у розрізі дискримінації права реалізації власної справи (етнічна / гендерна);

3) частка компаній, яка отримала дохід в 1 млрд. доларів США або вище, за регіонами (не містить інформацію про стартапи).

Показники мають кількісне співвідношення та підтвердженні статистикою дані, що є перевагою даного методичного підходу. Недоліком The State of European Tech $є$ те, що оцінка подана лише у розрізі регіонів Свропи, інші континенти не розглядаються. Немає чіткого розподілу на стартапи та стартапи, що створюють студенти.

European Startup Monitor (Німеччина) [2]. Метою ESM - збір та аналіз даних про стартапи, для виявлення загальних проблем запуску та масштабування проектів у країнах, ЗВО та пошуку шляхів їх вирішення.

ESM базує своє дослідження на основі таких ознак: визначення стартапів; характеристика засновників; характеристика запуску проектів; створення робочих місць; міжнародне розширення проектів; проблеми (виклики) реалізації стартапів.

Показники ESM, що не досліджують стартапи, створені студентами:

1) створення нових робочих місць (містить загальну інформацію про новостворені робочі місця за регіонами);

2) інтернаціоналізація стартапів (розповсюдження за регіонами) (дані, сформовані на опитуванні окремої частини респондентів).

Перевага ESM - опрацювання великої бази даних, партнерство з провідними компаніями та 3BO, що підсилює правдивість отриманих даних. Недоліком ESM є те, що окремо не піддається аналізу процес створення стартапів студентами за підтримки 3ВО.

German Startup Monitor (Німеччина) [4]. Основні цілі GSM - представити значення стартапів, окреслити економічні ініціативи щодо зміцнення місцезнаходження 
Німеччини та іiі регіональних екосистем, а також заохотити молодь до підприємництва.

GSM розглядає стартапи, які: молодші 10-и років, мають інноваційні технології та / або бізнес-моделі та мають або прагнуть до залучення співробітників.

Показників GSM, які досліджують стартапи, створені студентами:

1) середній розмір команди у регіонах Німеччини;

2) диференціація стартапів за сферами спрямування;

3) диференціація стартаперів за статтю / віком;

4) рейтингування німецьких університетів за кількістю створених стартапів.

До показників GSM, які не досліджують стартапи, створені студентами відносяться:

1) наслідки кризи Covid 19 у промисловості Німеччини;

2) заходи підтримки, що використовуються для зменшення впливу кризи Covid 19 на економіку країни.

German Startup Monitor засновано на онлайн-опитуванні керівників німецьких стартапів. Використовуючи опитування, як засіб аналізу стартап-руху, слід зважати, що воно має суб'єктивний характер. Це, у свою чергу, позбавляє дослідження системності, формальної несуперечності та неупередженості.

QS World University Rankings (Великобританія) [6]. Рейтинг QS оцінює університети за шістьма показниками: дослідницька діяльність, викладання, думка роботодавців і кар'єрний потенціал, кількість іноземних студентів і викладачів.

Відповідно до цього ранжування, ЗВО групують відповідно до комбінації показників добробуту, наукових досягнень, успіхів студентів, підприємницьких здобутків тощо.

Проте, рейтинг, містить недостатньо матеріалу 3 питань підприємництва студентів, не кажучи вже про створення стартапів.

Startup Friendliness Index (США) [7]. SFI відображає привабливість стартапекосистем. Методичний процес SFI складається із таких етапів:

1) вибір та розмежування показників (65 показників) за категоріями (6 категорій): ринок (розподіл галузей за перспективністю), людський капітал (студенти-підприємці, найманні працівники), фінансування, інфраструктура, макропоказники (політична стабільність, оподаткування, рівень злочинності т.п.), тип підтримки бізнесу (акселератори, інкубатори, коворкінг);

2) прирівнювання значень отриманих показників за 100-ою шкалою;

3) агрегація даних.

Перевагою даного індексу є всеохопність цілого світу, де створюються стартапи. Це стає можливим за рахунок співпраці SFI 3 Google Maps. Недоліком даного методичного підходу - фрагментість, оскільки досліджує екосистему з окремих позицій.

Global Innovation Index (Швейцарія) [5]. GII - індекс, що відображає стан та рівень розвитку інновацій у країнах зі сторони різних категорій: державні інститути, університети, людський капітал тощо. Починаючи з 2007 року, формуванням індексу займаються Корнельський університет (США), Школа бізнесу INSEAD (Франція) і Всесвітня організації інтелектуальної власності.

Методичний процес GII складається із таких етапів:

1) збір та аналіз даних за 80 показниками різних категорій;

2) прирівнювання значень отриманих показників за 100-ою шкалою;

3) агрегація даних / присвоювання відповідного значення.

Показники GII, які не використовуються для аналізу стартапів, створених студентами:

1) рейтингування науково-технічних кластерів (стартапи не включаються у рейтинг); 
2) аналіз джерел фінансування інновацій (усіх).

Global Innovation Index дозволяе проаналізувати переваги та недоліки інноваційного клімату країни та окремих іiі позицій. Проте, він не аналізує окремо стартап-рух молоді.

Кожний із розглянутих методичних підходів аналізує досліджувані стартапи на певному етапі життєвого циклу проекту. Розмежуємо вищеописані методичні підходи у розрізі життєвого циклу стартапу та підходів до управління (табл. 1).

Таблиця 1

Класифікація методичних підходів до аналізу створення стартапів студентами у розрізі життєвого циклу стартапу та підходів до управління

\begin{tabular}{|c|c|c|c|}
\hline Методичний підхід & $\begin{array}{c}\text { Показник, що можна використати для } \\
\text { авторського методичного підходу }\end{array}$ & Підхід & $\begin{array}{r}\text { Етапи ЖЦ } \\
\text { стартапу }\end{array}$ \\
\hline 1 & 2 & 3 & 4 \\
\hline $\begin{array}{l}\text { UBI Global World Rankings of } \\
\text { Business Incubators \& } \\
\text { Accelerators (Швеція) [11] }\end{array}$ & $\begin{array}{l}\text { - рейтинг університетських інкубаторів та } \\
\text { їх партнерські зв'язки; } \\
\text { - проекти } 3 \text { найбільшими обсягами } \\
\text { залучених інвестицій за країнами та } \\
\text { університетами; }\end{array}$ & процесний & exit stage \\
\hline $\begin{array}{l}\text { Методичний підхід на основі } \\
\text { моделі «потрійної спіралі» Г. } \\
\text { Іцковіца і Л. Лейдесдорффа } \\
\text { (Росія) }[1, \text { с. } 81]\end{array}$ & $\begin{array}{llr}\text { - } \quad \text { перелік } & \text { способів } & \text { фінансового } \\
\text { забезпечення } & \text { стартапів, } & \text { створених } \\
\text { студентами; } & & \end{array}$ & процесний & $\begin{array}{l}\text { startup } \\
\text { stage }\end{array}$ \\
\hline $\begin{array}{l}\text { The Female Founders Monitor } \\
\text { (FFM) (Німеччина) [9] }\end{array}$ & $\begin{array}{l}\text { - гендерний } \quad \text { розподіл засновників } \\
\text { стартапів, створених студентами; } \\
\text { - } \quad \text { фінансове забезпечення стартапів, } \\
\text { створених студентами; }\end{array}$ & системний & exit stage \\
\hline \begin{tabular}{lrr} 
European & \multicolumn{2}{r}{ University } \\
Association & EUA & Study \\
(Бельгія) [3] & &
\end{tabular} & $\begin{array}{l}\text { - рейтинг університетів, при яких } \\
\text { створювалися стартапи; } \\
\text { - середня кількість засновників стартапу, } \\
\text { створеного при ЗВО; } \\
\text { - найпоширеніші сфери реалізації } \\
\text { стартапів, створених студентами; }\end{array}$ & системний & exit stage \\
\hline $\begin{array}{l}\text { The State of European Tech } \\
\text { (Великобританія) [10] }\end{array}$ & $\begin{array}{l}\text { - гендерний розподіл засновників } \\
\text { стартапів, створених студентами за } \\
\text { регіонами; } \\
\text { - відсоткове співвідношення віку } \\
\text { засновників групи проекту за регіонами; } \\
\text { - середня кількість засновників стартапу, } \\
\text { створеного при 3ВО; } \\
\text { - частка студентських патентів, поданих за } \\
\text { регіонами походження; }\end{array}$ & системний & exit stage \\
\hline Startup Ranking (Перу) [8] & $\begin{array}{l}\text { - } \text { найпоширеніші сфери реалізації } \\
\text { стартапів; } \\
\text { - перелік способів фінансування } \\
\text { стартапів; }\end{array}$ & структурний & $\begin{array}{l}\text { expansion } \\
\text { stage }\end{array}$ \\
\hline $\begin{array}{l}\text { European Startup Monitor } \\
\text { (Німеччина) [2] }\end{array}$ & $\begin{array}{l}\text { - } \quad \text { відсоткове співвідношення віку } \\
\text { засновників групи проекту за регіонами; } \\
\text { - } \quad \text { гендерний розподіл засновників } \\
\text { стартапів, створених студентами; }\end{array}$ & структурний & exit stage \\
\hline $\begin{array}{l}\text { German } \quad \text { Startup } \\
\text { Monitor (Німеччина) [4] }\end{array}$ & $\begin{array}{l}\text { - середня кількість засновників стартапу, } \\
\text { створеного при ЗВО; } \\
\text { - сфери реалізації стартапів; }\end{array}$ & процесний & exit stage \\
\hline $\begin{array}{l}\text { QS World } \quad \text { University } \\
\text { Rankings (Великобританія) } \\
\text { [6] }\end{array}$ & $\begin{array}{l}\text { - рейтинг ЗВО відповідно до створення } \\
\text { кваліфікованих кадрів; }\end{array}$ & системний & $\begin{array}{l}\text { expansion } \\
\text { stage }\end{array}$ \\
\hline
\end{tabular}




\begin{tabular}{|c|c|c|c|}
\hline & & \multicolumn{2}{|c|}{ Продовж. табл. } \\
\hline 1 & 2 & 3 & 4 \\
\hline $\begin{array}{l}\text { Startup Friendliness } \\
\text { (США) [9] }\end{array}$ & $\begin{array}{l}\text { - рейтингування країн за типом підтримки } \\
\text { стартапів; }\end{array}$ & процесний & $\begin{array}{l}\text { growth } \\
\text { stage }\end{array}$ \\
\hline $\begin{array}{l}\text { Global Innovation } \\
\text { (Швейцарія) [5] }\end{array}$ & $\begin{array}{l}\text { - } \text { рейтинг залучених } \\
\text { країнами та інститутами. }\end{array}$ & процесний & $\begin{array}{l}\text { startup } \\
\text { stage }\end{array}$ \\
\hline
\end{tabular}

Класифікація методичних підходів до аналізу створення стартапів студентами у розрізі життєвого циклу стартапу та підходів до управління дає можливість виявити показники, які можна використати у авторській методиці аналізу.

Так, аналіз стартапів, створених студентами на стадії запуску (startup stage) краще здійснювати за допомогою Global Innovation Index та методичного підходу сформованого на основі моделі «потрійної спіралі». Вони допоможуть з'ясувати рівень інвестиційної привабливості регіонів, розміщення потенційних інвесторів тощо.

Аналіз стартапів, створених студентами на стадії зростання (growth stage) доцільно проводити на основі Startup Friendliness Index. Оцінка проектів на стадії розширення (expansion stage) стає можливою на основі QS World University Rankings та Startup Ranking.

Всі інші методичні підходи (UBI Global World Rankings of Business Incubators \& Accelerators, European Startup Monitor, The State of European Tech, European University Association EUA Study) допоможуть проаналізувати студентські проекти на стадії «виходу» (exit stage).

Отже, дослідження існуючих методичних підходів щодо аналізу реалізації стартапів, створених студентами засвідчило про необхідність здійснення комплексного моніторингу i грунтовного відбору системи показників, що забезпечуватимуть цю комплексність.

Дослідження вищеописаних методичних підходів, дозволило сформувати авторський методичний підхід до аналізу створення стартапів студентами (див. рис. 1). Даний аналіз має включати такі етапи.

1. Перший етап передбачає обгрунтування мети аналізу. Мета нашого аналізу визначити особливості створення стартапів при університетах; розкриття основних проблем, що пригальмовують студентський стартап-рух.

2. Другий етап передбачає визначення напрямів аналізу створення стартапів при 3ВО, вибір яких спирається на визначальні ознаки:

- аналіз розвитку підприємницьких університетів;

- аналіз практики розвитку бізнес-інкубаторів при університетах зарубіжних країн;

- аналіз сфери реалізації та способів фінансування стартапів, створених студентами;

- аналіз засновників стартапів, створених студентами.

3. Третій етап передбачає вибір системи даних для аналізу згідно наведених напрямів аналізу. У нашому випадку, студентські проекти буде доцільно аналізувати за такаю системою даних (відповідно до 4-х визначальних ознак):

Перша визначальна ознака:

- частка студентських патентів, поданих за регіонами походження;

- ТОП-10 провідних університетів, при яких створювалися стартапи.

Друга визначальна ознака:

- ТОП-10 університетських інкубаторів та їх партнерські зв'язки;

- характеристика найбільш відомих студентських інкубаторів при ЗВО.

Третя визначальна ознака:

- найпоширеніші сфери реалізації стартапів, створених студентами; 
- перелік способів фінансового забезпечення стартапів, створених студентами; - проекти з найбільшими залученими інвестиціями за країнами та університетами.

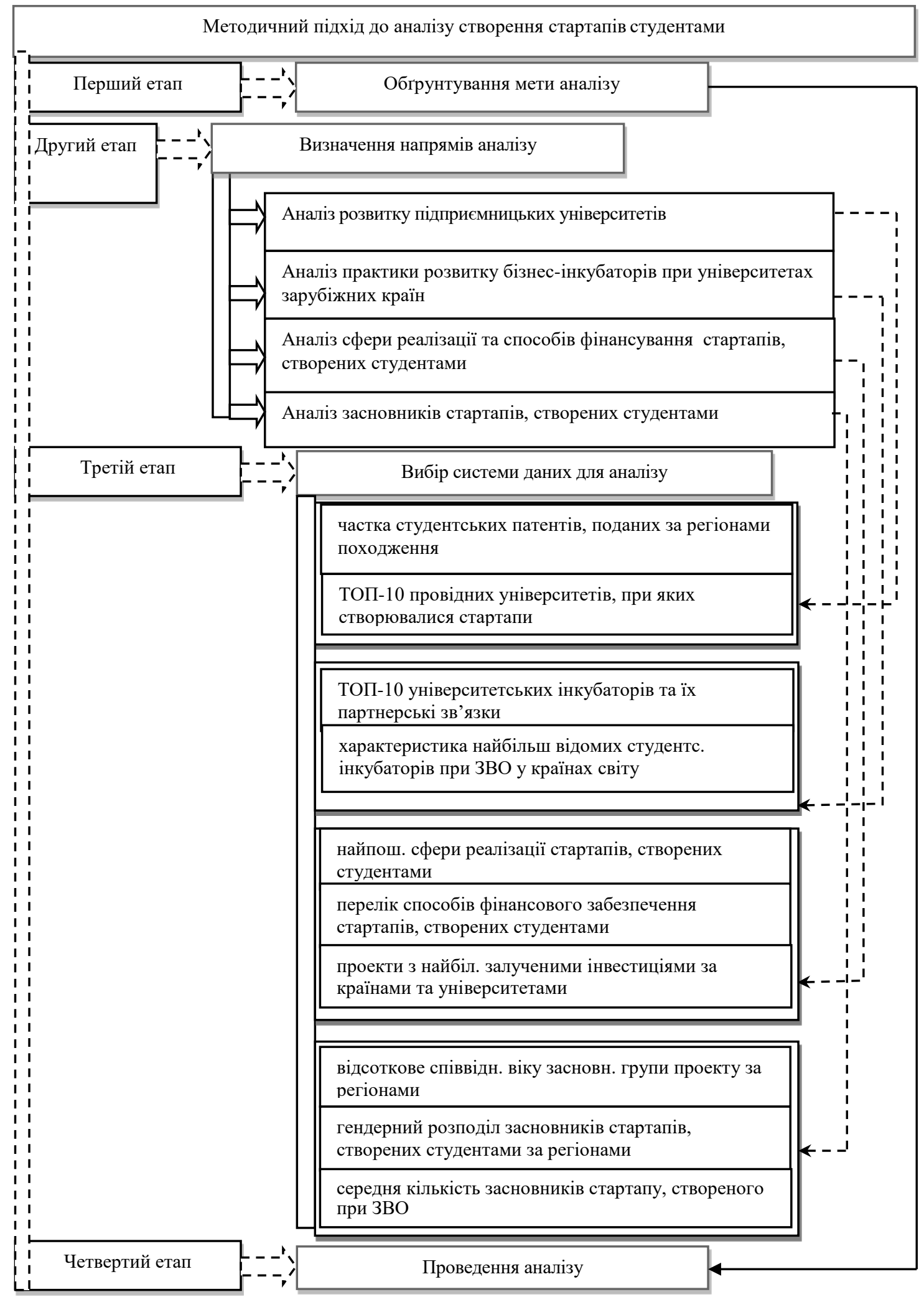

Рис. 1. Методичний підхід до аналізу створення стартапів студентами

Четверта ознака:

- відсоткове співвідношення віку засновників стартапів за регіонами; 
- гендерний розподіл засновників стартапів, створених студентами за регіонами; - середня кількість засновників стартапу, створеного при закладах вищої освіти.

4. Четвертий етап - власне оцінка стартапів, створених студентами. На даному етапі проводяться розрахунки відповідно до обраних визначальних ознак.

Висновки. Запропонований методичний підхід дозволить кількісно та якісно охарактеризувати практику розвитку бізнес-інкубаторів при університетах зарубіжних країн; сфери реалізації стартапів, створених студентами; способи фінансування стартапів, створених студентами, а отже, представити загальну картину щодо розвитку стартапів при ЗВО.

\section{Список бібліографічного опису}

1. Артемова В.И., Малова А.С., Мухачева А.В. Функционирование бизнес-инкубаторов при университетах Европы, Северной Америки и Азии. Инновации. №7. 2016 (213). С. 75-86.

2. European Startup Monitor. URL: http://startupmonitor.eu (дата звернення: 17.05.2021).

3. European University Association EUA Study. URL: https://eua.eu (дата звернення: 17.05.2021).

4. German Startup Monitor. URL: https://deutscherstartupmonitor.de (дата звернення: 17.05.2021).

5. Global Innovation Index. URL: https://www.globalinnovationindex.org (дата звернення: 17.05.2021).

6. QS World University Rankings. URL: https://www.topuniversities.com/university-rankings/world-university-rankings/2021 (дата звернення: 17.05.2021).

7. Startup Friendliness Index. URL: https://enpact.org/data-research/startup-friendliness-index (дата звернення: 17.05.2021).

8. Startup Ranking. URL: https://www.startupranking.com (дата звернення: 17.05.2021).

9. The Female Founders Monitor (FFM). URL: https://femalefoundersmonitor.de/en (дата звернення: 17.05.2021).

10. The State of European Tech. URL: https://2020.stateofeuropeantech.com (дата звернення: 17.05.2021).

11. UBI Global World Rankings of Business Incubators \& Accelerators 2020-2021. URL: https://www.researchgate.net/publication/338992258 (дата звернення: 17.05.2021).

\section{References}

1. Artemova V.Y., Malova A.S., Mukhacheva A.V. Funktsyonyrovanye byznes-ynkubatorov pry unyversytetakh Evropy, Severnoy Ameryky y Azyy. Ynnovatsyy. No7. 2016 (213). S. 75-86. [in Russian].

2. European Startup Monitor. URL: http://startupmonitor.eu.

3. European University Association EUA Study. URL: https://eua.eu.

4. German Startup Monitor. URL: https://deutscherstartupmonitor.de.

5. Global Innovation Index. URL: https://www.globalinnovationindex.org.

6. QS World University Rankings. URL: https://www.topuniversities.com/university-rankings/world-universityrankings/2021.

7. Startup Friendliness Index. URL: https://enpact.org/data-research/startup-friendliness-index.

8. Startup Ranking. URL: https://www.startupranking.com.

9. The Female Founders Monitor (FFM). URL: https://femalefoundersmonitor.de/en.

10. The State of European Tech. URL: https://2020.stateofeuropeantech.com.

11. UBI Global World Rankings of Business Incubators \& Accelerators 2020-2021. URL: https://www.researchgate.net/publication/338992258.

Дата подання публікації 15.07.2021p. 